\title{
INTERthesis
}

\section{MÍDIA E DEFICIÊNCIA: UMA ABORDAGEM INTERDISCIPLINAR}

\section{Melina de La Barrera Ayres ${ }^{1}$}

Adriano Henrique Nuernberg ${ }^{2}$

Carmen Silvia Rial ${ }^{3}$

\section{Resumo:}

Neste artigo refletimos sobre a abordagem da deficiência física adquirida proposta pela telenovela Viver a Vida (escrita por Manoel Carlos; produzida e veiculadas pela Rede Globo em 2009 e 2010) e o blog Sonhos de Luciana (REDE GLOBO, 2010). Para tanto, analisamos a cena em que Luciana, protagonista desta temática, vai pela primeira vez à praia após ter adquirido a deficiência. Partindo de uma perspectiva interdisciplinar estabelece-se um diálogo entre três áreas de conhecimento: a Comunicação Social (fundamentalmente os Estudos Culturais) que ampara a perspectiva a partir da qual se entende a mídia; a Antropologia, área que contribui com o olhar e a metodologia, a etnografia de tela; e os Disability Studies, que fornecem o embasamento teórico para a análise da deficiência.

Palavras-chave: Telenovela, Deficiência, Interdisciplinaridade, Etnografia de tela.

\section{PONTO DE PARTIDA}

O termo deficiência remete a um grande conjunto de vivências e evoca tipos de realidades diferentes (SHAKESPEARE, 2007). A diversidade desta vivência evidencia-se tanto em sua prevalência na população mundial - cerca de um bilhão de pessoas-, bem como em sua relação com o ciclo de vida humano - todas as pessoas em algum momento da vida podem vivenciar a deficiência (DINIZ, 2007).

Neste contexto, a mídia cumpre um papel central na transmissão de informações. A mídia em geral, e as telenovelas brasileiras em particular, têm se tornado um "espaço público" (LOPES, BORELLI, RESENDE, 2002), onde ficção e contexto social constroem um diálogo e (re)negociam significados. Partindo deste

\footnotetext{
1 Doutora em Ciências Humanas pelo Programa Interdisciplinar em Ciências Humanas e pósdoutoranda em Jornalismo ambos na Universidade Federal de Santa Catarina, Florianópolis, SC, Brasil. E-mail: melina.ayres@gmail.com

2 Doutor em Ciências Humanas pela Universidade Federal de Santa Catarina. Professor Associado do Departamento de Psicologia da Universidade Federal de Santa Catarina, Florianópolis, Brasil. Email: adrianoh@cfh.ufsc.br

${ }^{3}$ Doutora em Antropologie et Sociologie pela Université de Paris V, França. Pós-doutorados na Universite de Toulouse e no College de France, França. Professora Titular do Departamento de Antropologia da Universidade Federal de Santa Catarina, Florianópolis, SC, Brasil. E-mail: rial@cfh.ufsc.br
}

R. Inter. Interdisc. INTERthesis, Florianópolis, v.13, n.3, p.61-80 Set.-Dez. 2016 
entendimento, neste artigo refletiremos sobre a abordagem da deficiência física adquirida proposta pela telenovela Viver a Vida (escrita por Manoel Carlos; produzida e veiculadas pela Rede Globo em 2009 e 2010 às 21:00 horas). As informações com as que aqui trabalharemos fazem parte da pesquisa de Doutorado "As representações da deficiência física na telenovela Viver a vida. Uma etnografia de tela da intimidade: cuidado, corpo e sexualidade", defendida no Programa de Pós-Graduação Interdisciplinar em Ciências Humanas da Universidade Federal de Santa Catarina ${ }^{4}$.

Viver a vida dialoga com um contexto social específico, o Brasil de 2009, momento em que entrou em vigor a Convenção sobre os Direitos das Pessoas com Deficiência (BRASIL, 2011); ratificada pelo Congresso Nacional em julho de 2008. Esta Convenção garante os direitos básicos das pessoas com deficiência em equiparação de oportunidade aos serviços de saúde, reabilitação, educação, profissionalização, esporte, cultura e lazer (BRASIL, 2011). Para a construção de Luciana, a protagonista desta temática, o autor da telenovela, Manoel Carlos, se inspirou na história de vida da jornalista Flávia Cintra. Flávia foi consultora do autor e da atriz (Alinne Morais), buscando dar realismo ao tratamento da temática.

A abordagem proposta por Viver a vida teve ainda outros dois diferencias: o primeiro se refere à construção da história de Luciana. Neste caso, a deficiência não foi apresentada como uma "punição" para a personagem. No final da trama, Luciana, como toda mocinha, foi feliz, casou-se como o homem amado, teve filhos/as e sucesso na carreira como modelo, tudo isso tendo que se adaptar a nova realidade: viver e conviver com tetraplegia. O segundo diferencial refere-se ao modo como se construiu o relato. A Rede Globo, pela primeira vez, relatou a história da personagem através de duas narrativas, a telenovela e um blog; sendo que este último era, também, um canal de comunicação entre a personagem e o público. $\mathrm{O}$ Blog Sonhos de Luciana ${ }^{5}$ foi introduzido na trama a partir do momento em que a moça adquire a deficiência. Ela decide escrever o blog para compartilhar sua experiência de vida como mulher cadeirante. Neste espaço foram publicados, no

\footnotetext{
${ }^{4}$ Pesquisa realizada com Bolsa CAPES para o desenvolvimento da pesquisa no Brasil e CAPESCOFECUB para a realização de Doutorado Sanduíche na França.

${ }^{5} \mathrm{O}$ blog está disponível até hoje, junho de 2016, no endereço: <http://gshow.globo.com/novelas/vivera-vida/sonhos-de-luciana/platb/>
}

R. Inter. Interdisc. INTERthesis, Florianópolis, v.13, n.3, p.61-80 Set.-Dez. 2016 
total, 84 postagens (posts) com textos supostamente escritos pela personagem, abordando questões como: acessibilidade, rotina, tecnologias, cuidado, amor, etc. Estas postagens receberam um total de 13.021 comentários. Importante salientar que os relatos do blog não são uma continuação da telenovela, nem um resumo dos capítulos. Os posts possuem certa independência com a telenovela e entre si, podendo ser lidos separadamente sem respeitar uma sequência cronológica. Este tipo de narrativa que se apoia em diversas plataformas, onde cada uma explora a história de um modo diferente, fazendo com que os relatos se complementem ou façam sentido separadamente, denomina-se narrativa transmídia. Conforme Jenkins, esta é

[...] a arte da criação de um universo. Para viver uma experiência plena num universo ficcional, os consumidores devem assumir o papel de caçadores e coletores, perseguindo pedaços da história pelos diferentes canais, comparando suas observações com as de outros fãs, em grupos de discussão on-line, e colaborando para assegurar que todos os que investiram tempo e energia tenham uma experiência de entretenimento mais rica (JENKINS, 2009, p. 49).

Neste caso, telenovela e blog constroem uma história onde se reconhecem grande parte dos elementos presentes na narrativa trasmidiática. Portanto, ao reconhecer estas características do relato e a complexidade da deficiência, entendendo-a como uma vivência ampla e interseccionada ${ }^{6}$, faz-se necessária uma abordagem interdisciplinar, visto que a interdisciplinaridade apresenta um "[...] conjunto de princípios facilitadores do diálogo entre as disciplinas, de forma a permitir reestabelecer uma visão mais ampla e integradora do conhecimento e dos objetos do conhecimento" (FERNANDES, 2010, p. 75).

Partindo desta perspectiva estabeleceremos um diálogo entre três áreas de conhecimento: a Comunicação Social, a Antropologia e os Disability Studies. Dentro da área da Comunicação, centramo-nos na perspectiva dos Estudos Culturais que analisam a mídia no seu contexto social mais amplo, nas práticas cotidianas, partindo do pressuposto de que "o comportamento do público é orientado por fatores estruturais e culturais que, por outro lado, influenciam o conteúdo da mídia, justamente pela capacidade de adaptação e de aglomeração destes últimos" (WOLF, 2003, p. 104).

${ }^{6} \mathrm{O}$ termo intersecções foi criado pela jurista americana Kimberlé W. Crenshaw na década de 80 , buscando nomear de algum modo os dilemas estratégicos e identitários encontrados no espaço político, para categorizar as pessoas que sofrem formas de dominações combinadas como, por exemplo, as mulheres com deficiência (BERENI et al, 2012).

R. Inter. Interdisc. INTERthesis, Florianópolis, v.13, n.3, p.61-80 Set.-Dez. 2016 
No campo da Antropologia, dialogamos especificamente com a Antropologia Visual, que parte da compreensão da imagem como um construto cultural que pode ser aplicada tanto como um instrumento ou forma de registro de uma pesquisa antropológica, como ser a própria fonte da pesquisa (BARBOSA; DA CUNHA, 2006). De acordo com Ginsburg, a Antropologia Visual é a "[...] produção e análise das representações culturais fotográficas e/ou concebidas para a tela, ou, mais simplesmente, a interseção entre culturas e mídia (na tela)" (1999, p. 36). A Etnografia de tela é uma metodologia da Antropologia Visual. De cunho interdisciplinar, alia à análise do audiovisual (que combina conhecimentos sobre imagem, cinema, linguagem audiovisual, semiótica e sintaxe) à teoria e a metodologia antropológica. Conforme Rial, a Etnografia de tela

[...] apresenta a capacidade de revelar os "espaços sociais" da televisão, a etnografia (de tela ou de audiência) sendo assumida aqui como uma prática de trabalho de campo, fundada em uma prática de coleta e análise de dados extensa e longa, que permite aos pesquisadores atingirem um grau elevado de compreensão do grupo social ou do texto estudado, mantendo uma reflexividade (RIAL, 2004, p. 25).

Finalmente, os Disability Studies, vêm contribuir com um olhar particular sobre a deficiência. Os Disability Studies são o campo de estudos da deficiência que trabalham a partir do modelo social da deficiência. Esta perspectiva desloca a compreensão da deficiência do corpo lesado para o contexto, apontando para o peso das barreiras sociais. Partindo deste pressuposto a deficiência deixa de ser compreendida como uma "tragédia pessoal" (OLIVER, 2009) para ser entendida como um problema social, de direitos humanos, econômico e cultural. A deficiência começa a ser considerada, portanto, como um estilo de vida, "[...] uma possibilidade digna e constituinte da condição humana - as pessoas com deficiência são cidadãs, com direitos e deveres" (MELLO, 2014, p. 26). Este tripé (Comunicação, Antropologia e Disability Studies) é a base sobre a que se apoia a análise da cena na qual Luciana vai à praia pela primeira vez após ter adquirido a deficiência, e as duas postagens relacionadas a esta vivência, que foram publicadas no blog da personagem.

\section{LUCIANA NA PRAIA}

R. Inter. Interdisc. INTERthesis, Florianópolis, v.13, n.3, p.61-80 Set.-Dez. 2016 
A praia pode ser considerada um dos lugares mais inóspitos para uma pessoa com deficiência física. Locomover-se ali com uma cadeira de rodas não é uma tarefa fácil. No entanto, este foi o ambiente escolhido para que Luciana realizasse um de seus primeiros passeios ao ar livre, logo após ter adquirido a deficiência. Esta cena mostra, entre outras coisas, como muitas vezes as pessoas com deficiência vivenciam um coming out, que se produz no momento em que interagem com o espaço público e usufruem de seus direitos como qualquer cidadão. Em termos de Doufour:

Os deficientes também tem a necessidade de um coming out para poder passar de uma identidade negativa a uma identidade positiva. Essa passagem para uma afirmação positiva está ligada a uma desindividualização da temática da deficiência e a uma visão coletiva e política (DOUFOUR, 2011, p. 2, tradução nossa).

A cena começa com uma contextualização: um primeiro plano das cadeiras anfíbias $^{7}$ estacionadas na areia da praia. Há uma pessoa ajeitando os coletes salvavidas em cada uma delas. Ao fundo um grupo de pessoas com suas cadeiras de rodas conversam embaixo de barracas (no teto das barracas há o símbolo das pessoas com deficiência e o dizer: "Praia para todos").

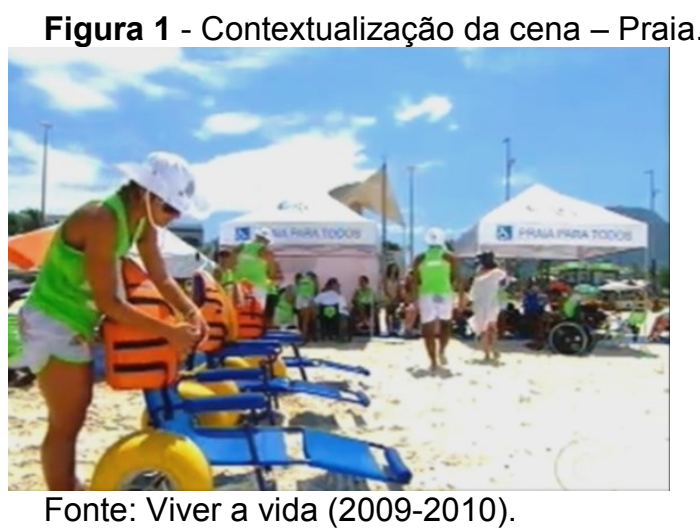

Em seguida, aparece Isabel (irmã de Luciana), junto a um rapaz, e a conversa se inicia:

Isabel: "Meninas, esse aqui é o Rafael” (VIVER A VIDA, 2009-2010).

\footnotetext{
${ }^{7}$ Este é o nome dado às cadeiras de rodas desenhadas para entrar na água.

R. Inter. Interdisc. INTERthesis, Florianópolis, v.13, n.3, p.61-80 Set.-Dez. 2016
} 
Luciana está acompanhada por Mia (sua irmã mais nova), Larissa (sua fisioterapeuta) e Tereza (sua mãe).

Figura 2 - Luciana e suas irmãs na praia.

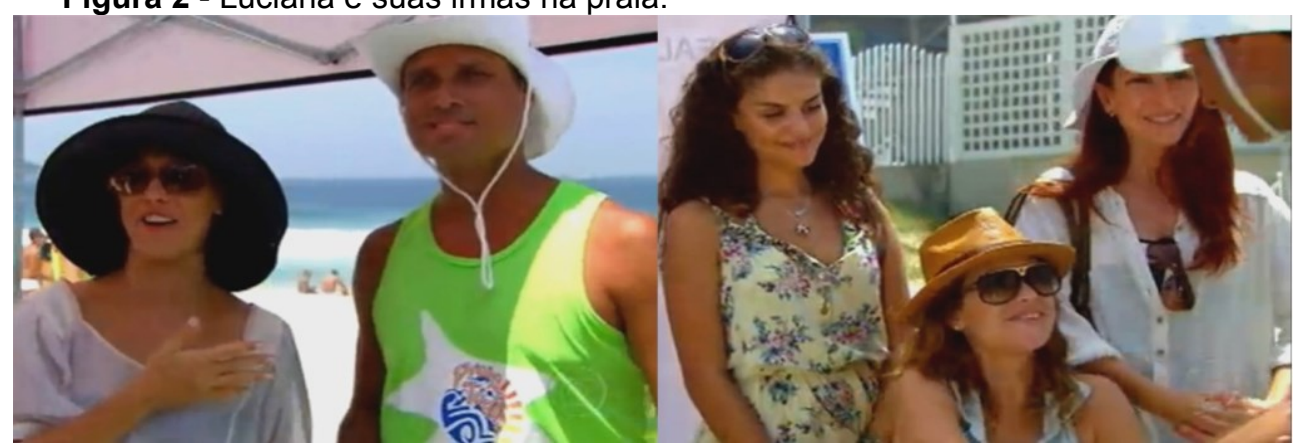

Fonte: Viver a vida (2009-2010).

Segue-se o diálogo:

Isabel: Rafael, essa aqui é minha irmã, Luciana. Ela vai precisar de uma mãozinha sua.

Rafael: Vamos lá?

Luciana: Vamos! Eu tô louca pra entrar no mar! Deixa eu te dizer uma coisa, o projeto, deve acontecer, sei lá, pra sempre! Em todas as localidades viu?!

Rafael: Mais essa é a proposta!

Luciana: Com certeza! Tem que aproveitar, né? A gente é muito privilegiada, esse mar, esse céu, Rio de Janeiro. Vamos lá! (VIVER A VIDA, 2009-2010).

O plano se abre e novamente vemos as cadeiras anfíbias sendo ajeitadas na areia. A música Fallin'for you, com uma melodia alegre e rítmica, acompanha o diálogo. Rafael vai buscar uma cadeira anfíbia.

Na sequência, o plano se abre e vemos três voluntários passando Luciana de sua cadeira de rodas para a cadeira anfíbia. Esta passagem demora poucos segundos, porém, a sequência registra o passo a passo e alguns detalhes, entre eles, a forma como as mãos e as costas de Luciana são seguradas.

Figura 3 - Passagem para cadeira anfíbia.

R. Inter. Interdisc. INTERthesis, Florianópolis, v.13, n.3, p.61-80 Set.-Dez. 2016 

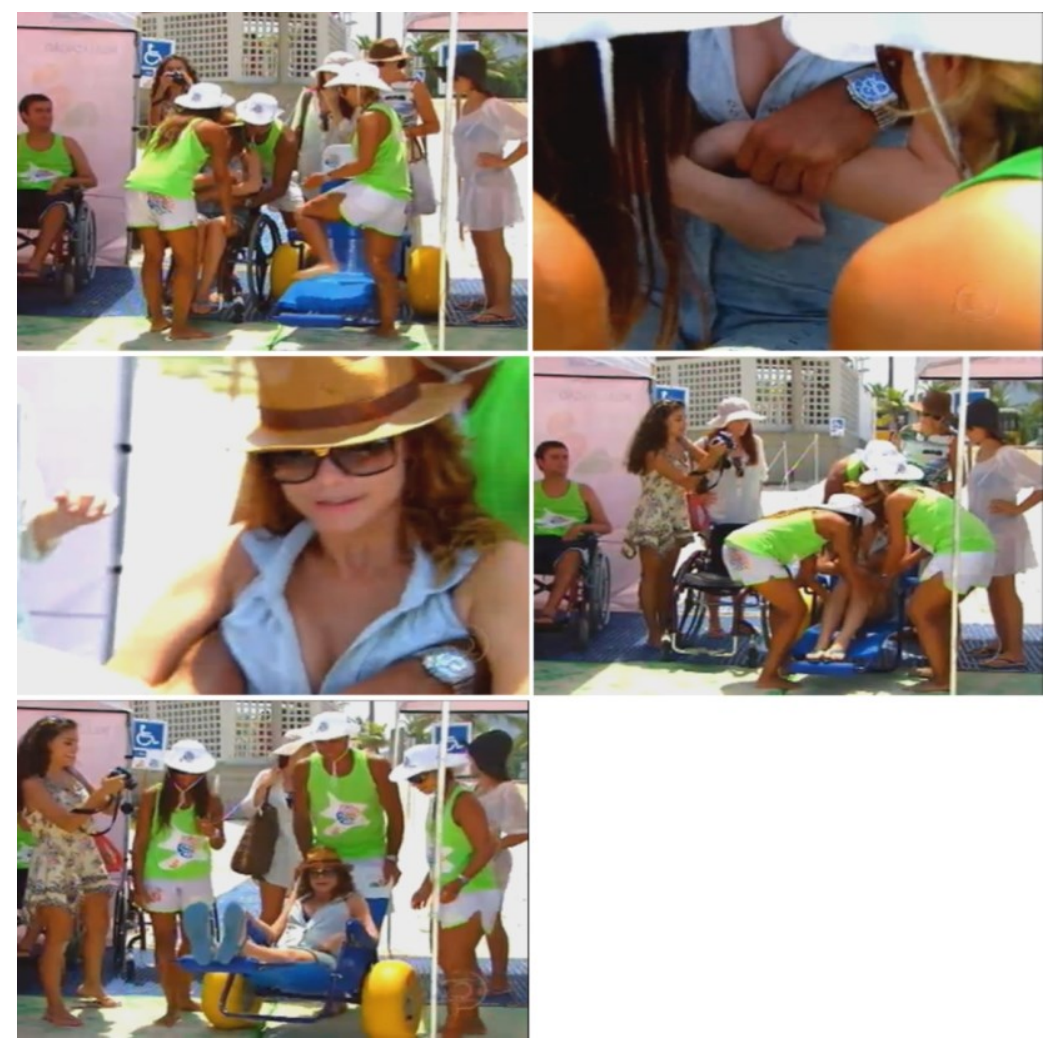

Fonte: Viver a vida (2009-2010).

Neste caso se os movimentos com o corpo de Luciana são registrados em seu passo a passo, toda a estrutura montada na praia para receber estas pessoas é colocada simplesmente como pano de fundo. Na pesquisa de campo, ao visitar trabalho realizado pela ADAPTSURF ${ }^{8}$, no Rio de Janeiro, observou-se como todos os equipamentos mostrados rapidamente na cena tem grande relevância. Por exemplo, a cadeira de rodas de Luciana está apoiada sobre um tapete azul (esteira). Este tapete é feito todo em metal e permite movimentar as cadeiras de rodas na areia, que de outro modo se enterrariam. A cadeira anfíbia é outro diferencial. De acordo com a equipe da ADAPTSURF, o banho de mar de pessoas com deficiência física ou mobilidade reduzida somente pode ser feito com segurança com estas cadeiras. Além disto, apesar de que a cena mostra um grupo de pessoas ajudando Luciana, em nenhum momento se esclarece que são profissionais capacitados para realizar estas ações. Entre os voluntários há professores de educação física, fisioterapeutas, etc. (DIARIO DE CAMPO, Rio de Janeiro, 18/03/2012).

\footnotetext{
${ }^{8}$ A ADAPTSURF é uma ONG que trabalha com pessoas com deficiência nas praias, promovendo a inclusão através do esporte. Como parte da pesquisa de Doutorado realizou-se uma visita a ONG e acompanhou-se o trabalho na praia em abril de 2012.
}

R. Inter. Interdisc. INTERthesis, Florianópolis, v.13, n.3, p.61-80 Set.-Dez. 2016 
Voltando à cena, Mia registra toda a ação com a câmera fotográfica, construindo um diálogo com o blog da personagem.

Mia: Olha aqui a fotinho para o blog!

Todas: Que linda! (VIVER A VIDA, 2009-2010).

O plano se abre e vemos Luciana sendo levada pela equipe de voluntários, sentada na cadeira anfíbia. Vale destacar que, durante o procedimento inicial, Luciana está toda vestida, usa: chapéu, camiseta, short, chinelos e ósculos de sol. No plano seguinte, Luciana aparece já de biquíni, sendo levada pela equipe em direção ao mar. Suas irmãs e a fisioterapeuta a seguem. A ação é acompanhada pela música, não há diálogos.

Figura 4 - Luciana e suas acompanhantes indo em direção ao mar.

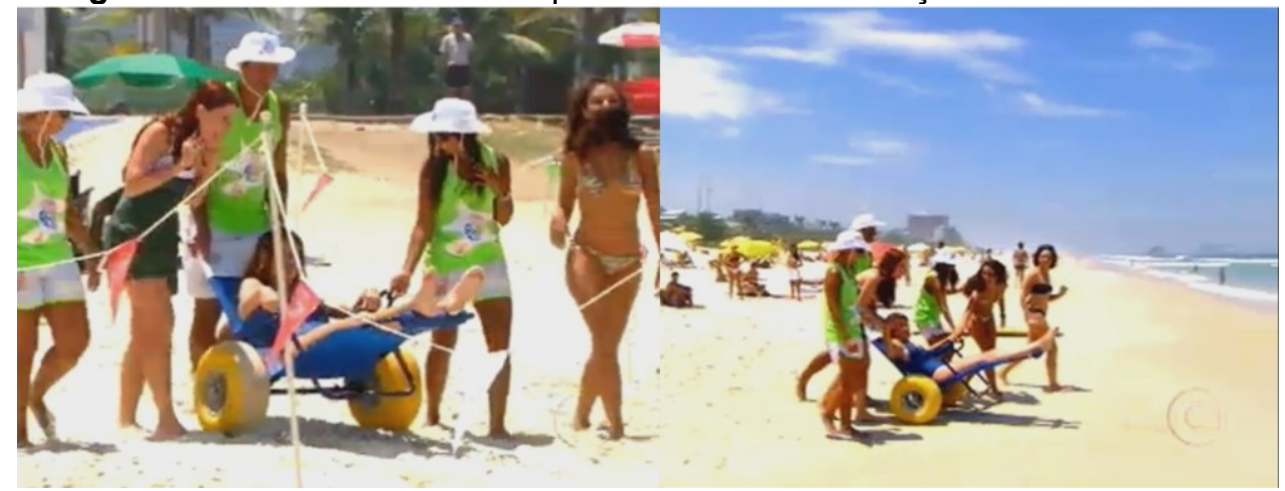

Fonte: Viver a vida (2009-2010).

Logo, uma panorâmica mostra a cadeira sendo colocada de costas e Luciana entrando no mar, junto aos voluntários e suas acompanhantes. Ela sorri o tempo todo, não demonstra medo ou insegurança. Ao fundo, já dentro da água, podemos ver outra pessoa usando uma cadeira anfíbia.

R. Inter. Interdisc. INTERthesis, Florianópolis, v.13, n.3, p.61-80 Set.-Dez. 2016 
Figura 5 - Luciana e suas acompanhantes no mar.

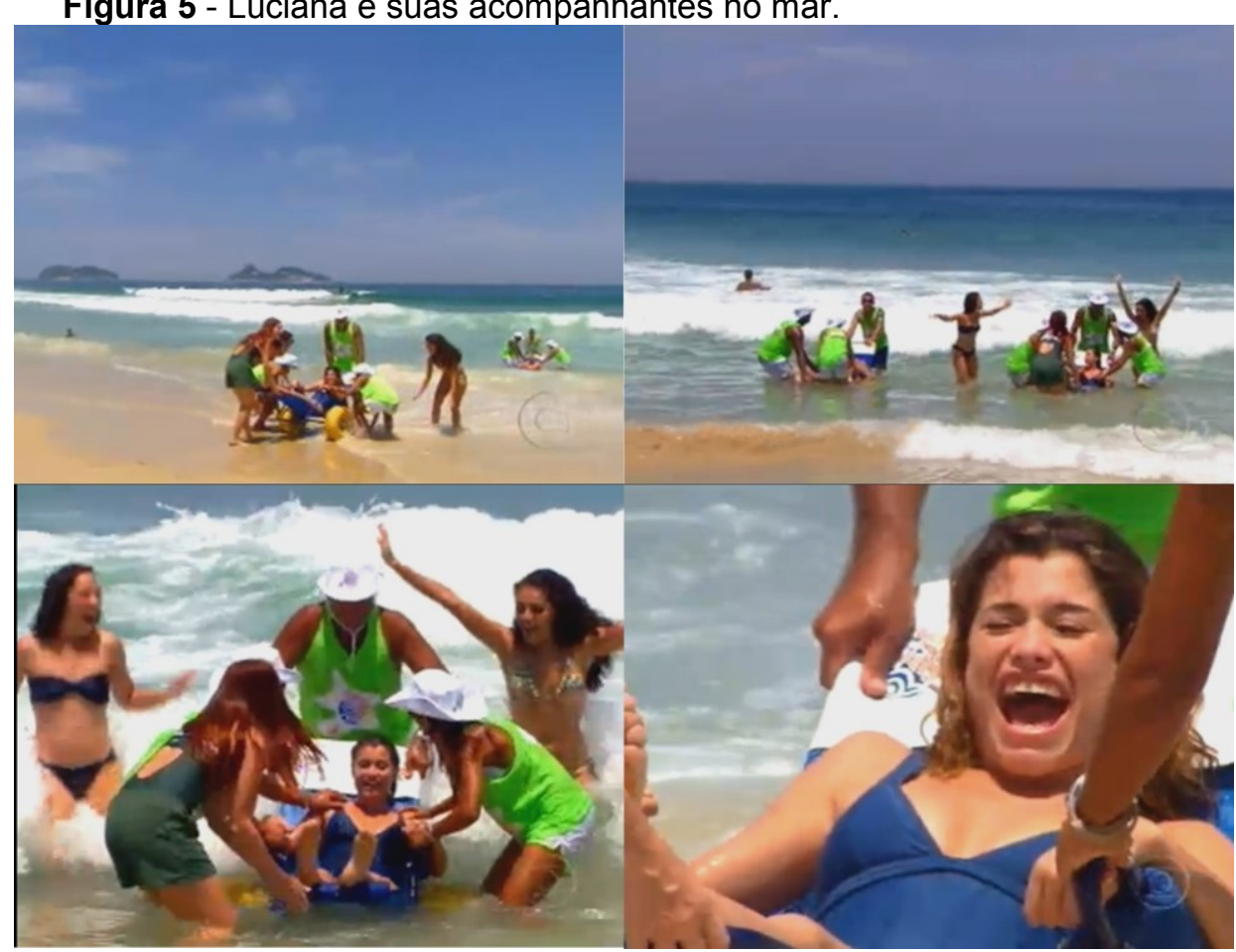

Fonte: Viver a vida (2009-2010).

Estas imagens são intercaladas com imagens de Tereza, que ficou na areia tirando fotos. Em seguida, uma câmera colocada dentro da água registra a diversão do grupo. Todos/as se molham com as ondas, riem e a cena termina. Todo esse processo dentro da água não tem diálogo, somente a música animada acompanha as imagens.

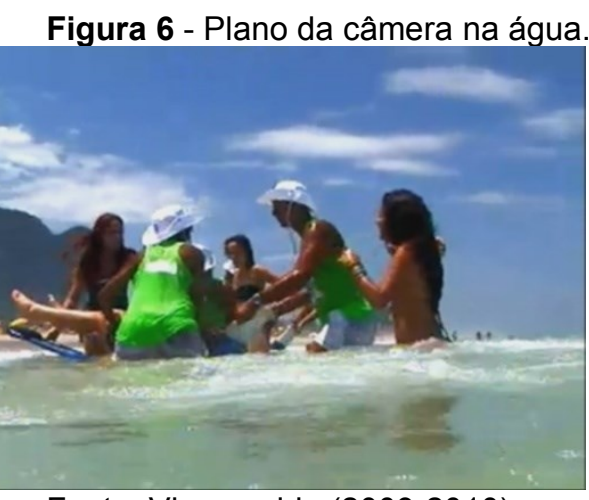

Fonte: Viver a vida (2009-2010).

Esta cena pode ser interpretada como um ritual de passagem e agregação. De acordo com Arnold Van Gennep (2008), os rituais são aqueles momentos que fazem parte da essência de viver, relativos à mudança e transição, tanto de pessoas como de grupos, para novos status ou etapas de suas vidas. Conforme o autor, estes rituais possuem uma estrutura que é universal, dividida em três grandes momentos: primeiro ocorre a separação das condições sociais prévias; logo há um

R. Inter. Interdisc. INTERthesis, Florianópolis, v.13, n.3, p.61-80 Set.-Dez. 2016 
estágio limiar, uma zona de fronteira - onde se produz a transição - e, por último, ocorre a incorporação da nova situação/condição.

Na cena, Luciana é recebida na praia por Rafael, um integrante da ONG, quem vai buscá-la na areia e lhe apresenta o projeto. É ele quem a conduz todo o processo: primeiramente, com a chegada a praia, ocorre a separação das condições sociais prévias; logo, o estágio limiar, que está composto pelo momento em que ela conversa com Rafael e suas acompanhantes até que entram na água. No processo limiar realiza-se a mudança de vestimenta: Luciana, que chaga a praia toda vestida fica de biquíni. Com a entrada na água efetivamente se incorpora a nova condição. No dizer de Ashenburg "submergir na água e emergir dela é uma maneira universal de declarar 'abandono o velho, passo a conviver com o novo'” (2008, p. 15). A água é, nesta cena, o elemento transformador (TURNER, 1974) que reintegrada Luciana à sociedade.

A intenção de divulgar esta vivência de Luciana na praia viu-se reforçada pelo blog, onde mereceu duas postagens, uma prévia a vista e outra posterior. No post prévio, mencionam-se detalhes dos equipamentos que a cena omite. A esteira, as cadeiras anfíbias, assim como a presença dos profissionais, são citadas.

Figura 7 - Blog Dia 12 - Postagem anterior à visita a praia.

\section{Dia 12 - Lá vem o sol, tchurururu!}

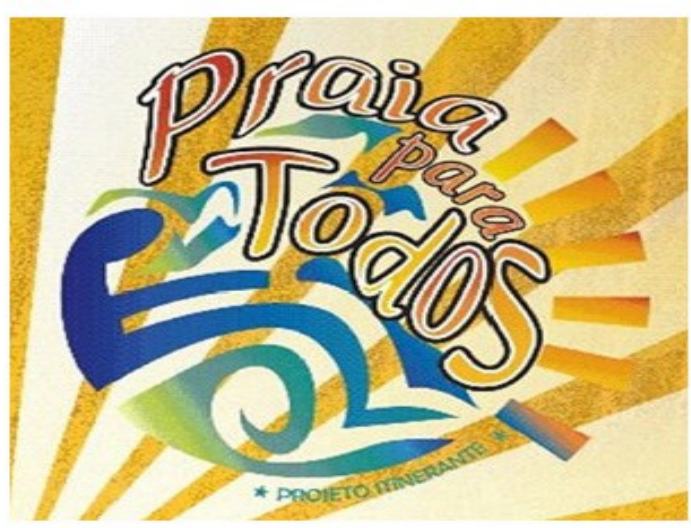

Fonte: Globo.com (2010b)
As soluções são simples e nos dão uma liberdade incrível! Além da esteira para passagem de cadeiras de rodas, há sinalização sonora, piso tátil para deficientes visuais, as cadeiras anfíbias e de banho, vagas de estacionamento reservadas, rampas de acesso à areia e tendas. O projeto também oferece atividades de recreação e esportivas, como o surfe adaptado, o voleibol sentado de praia, os tradicionais futebol e frescobol. Todas as atividades são realizadas com orientação de profissionais especializados, além de voluntários. Até o fim do verão, eles estarão em diferentes praias da cidade, de Copacabana ao Piscinão de Ramos. Não é bac ana? Dia desses apareço por lá, com certeza!

R. Inter. Interdisc. INTERthesis, Florianópolis, v.13, n.3, p.61-80 Set.-Dez. 2016 
No post posterior à visita, Luciana conta brevemente sua experiência, referese novamente aos equipamentos e fala sobre outros esportes que também podem ser praticados na praia. Nem todos os esportes citados fazem parte do trabalho da ONG na praia, eles foram incluídos para a cena. Na postagem também há fotografias e uma entrevista realizada em vídeo. No final da postagem ela diz que entrará "na política, só para apoiar projetos como esse", fazendo referência à importância do trabalho dos movimentos sociais. Deste modo, a história da telenovela ganha novos traços, construindo uma narrativa transmidiática (JENKINS, 2009).

Figura 8 - Blog Dia 22 - Postagem posterior à visita a praia.

\section{Dia 22 - Dia de luz, festa do sol}

qua, 03/03/10 por Luciana | categoria Projetos bacanas | tags Praia para todos

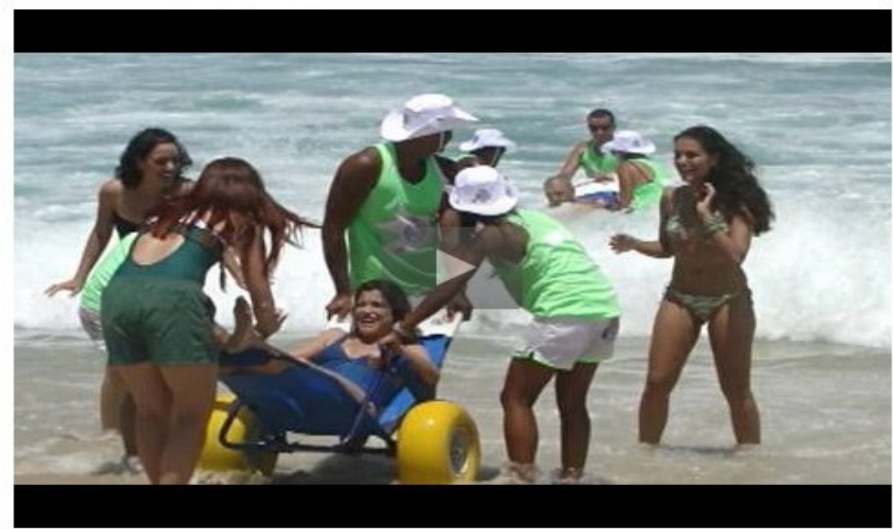

Gente, fui conferir de perto o projeto Praia para todos e AMEI! Vocês não imaginam minha felicidade. Não precisei ser carregada para chegar pertinho do mar - a esteira que eles coloc am a partir do calçadão é perfeita! E a cadeira anfíbia, própria para entrar no mar, é TUDO! Muita gente estava entrando no mar pela primeira vez, foi demais vivenciar tudo aquilo. O Rafael, um dos integrantes do projeto, foi extremamente atencioso comigo.

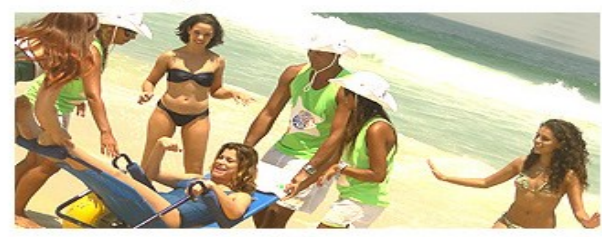

Ele me coloc ou na cadeira anfíbia e me deixou super tranqüila. Foi tão bac ana ver o pessoal jogando vôlei, frescobol, surfando e curtindo um dia de praia... Tiramos várias fotos para mostrar a vocês. Vejam aí

Ah, e gravei entrevistas em vídeo com o Ricardo Gonzalez, um dos idealizadores do projeto, tetraplégico como eu e com o Jefferson

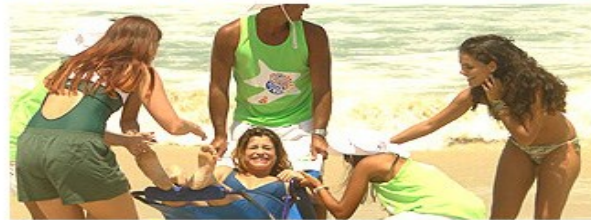
Maia, que também adora curtir o mar. Ambos muito bac anas!

Iniciativas como essa deveriam durar o ano todo. Acho que vou entrar para a Polític a só para apoiar projetos como esse, o que vocês acham?

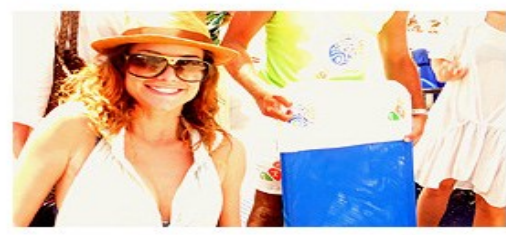

Fonte: Globo.com (2010d)

R. Inter. Interdisc. INTERthesis, Florianópolis, v.13, n.3, p.61-80 Set.-Dez. 2016 
Nos comentários dos dois posts o público parabeniza a divulgação, aproveita para reclamar mais inclusão e acessibilidade e destaca constantemente a felicidade da personagem ao entrar na água. Frases como "foi maravilhoso ver você feliz", "como você estava feliz", "sua felicidade é contagiante", "fiquei feliz por ver você se divertindo na praia", repetem-se em quase todos os comentários.

Maria do Carmo Giannini Balekjian, por exemplo, conta a vivência da deficiência de sua filha e as diversas dificuldades de acessibilidade pela qual passam diariamente:

Olá Luciana, Aproveitando quero cumprimentar o Rio de Janeiro pela excelente inciativa do fabuloso "Praia para Todos" e como você garanto que minha filha Marina também iria amar entrar na agua como você. Aproveitando o embalo Luciana, gostaria de deixar registrado aqui no seu blog o triste caso de desrespeito a ocupação de vagas para deficientes por pessoas para la de normais [...] Outra coisa que quero insistir é a questão da acessibilidade também: estamos muito longe ainda. Os estabelecimentos comerciais não se adequam a isso...vide as reformas que são feitas: onde está o acesso? Porque o deficiente tem que ficar confinado? Não e justo. [...] Beijos e lutar...sempre. Desistir jamais. (SONHOS DE LUCIANA, 03/03/2010, sic).

No texto de Maria do Carmo, fica claro que, apesar de que a telenovela está fazendo a divulgação de uma ação que é realmente positiva, ainda há muito por ser feito, e isto a telenovela não diz. A abordagem, neste caso, é bastante limitada. Esta limitação parece ainda mais clara no comentário de Lucia Neide Vieira de Mendonça, que vive no Canadá e compartilha como é a situação nesse país.

\begin{abstract}
Oi Luciana, vejo a dificuldade dos cadeirantes ai no Brazil, dificuldade em todos os sentidos, no simples ato de subir uma calcada o quanto eh dificil, eu me acostumei vendo cadeirantes com rotina de pessoas que nao tem esse problema, pois, moro em Toronto, tudo aqui no pais eh adaptado, o cadeirante nao precisa de ajuda de outra pessoa em nada, nas estacoes do Metro tem os elevadores para o facil acesso, as calcadas sao rebaixadas, todos os onibus do transporte coletivo sao adaptados, as escolas, teatros, cinemas, calcadoes das praias, o nosso Brazil eh maravilhoso, mas ainda precisa melhorar muito com relacao as carencias da populacao, um dia chegaremos la, adorei o seu blog, parabens pela sua determinacao, fique bem. God bless you always, byebye (SONHOS DE LUCIANA, 2010, sic).
\end{abstract}

Reforçando a abordagem da telenovela e do blog, uma reportagem do programa jornalístico da Rede Globo, o Fantástico, do dia 7 de março de 2010, também se referiu as atividades disponibilizadas na praia do Rio de Janeiro, para pessoas com deficiência. No texto se esclarece que a atividade realizada pela personagem não faz parte somente da ficção, mas é uma realidade disponível para quem tenha interesse: "Esta semana o público de Viver a Vida viu Luciana tomando banho de mar. A cena da fiç̧ão já é possível na realidade" (FANTÁSTICO, 2010). Na mesma 
reportagem há uma entrevista a Flávia Cintra, quem falou a respeito da atividade: "Com a ajuda de qualquer pessoa você pode entrar na água. Você não precisa ser carregado. Basta que a pessoa ajude a conduzir a cadeira. Isso é sensacional! É uma delícia!" (FANTÁSTICO, 2010); estimulando, assim, a que as pessoas com deficiência participem e se integrem a atividades ao ar livre.

\section{MÍDIA E DEFICIÊNCIA}

A mídia é mediadora e produtora de significados. Ao mesmo tempo em que retrata o contexto social, faz parte dele e o transforma. Por seu alcance possui um grande poder divulgador, disseminador de ideias novas e/ou preconcebidas. No Brasil, as telenovelas são uma das principais produções midiáticas. Produtos destinados ao entretenimento, que também cumprem o papel de "espaço público" (LOPES, 2009), onde de segunda a sábado se abordam diversos problemas sociais que estão candentes em nossa sociedade no momento de sua veiculação.

A cena da primeira visita de Luciana à praia é uma amostra do diálogo construído entre a telenovela Viver a Vida e o contexto social. A partir dela enviamse diversas mensagens que fazem parte do diálogo entre a telenovela e a Convenção sobre os Direitos das Pessoas com Deficiência (BRASIL, 2011); a telenovela e o Modelo Social da Deficiência; a telenovela e a vivência das pessoas com deficiência no Brasil, a partir do olhar da Rede Globo.

A cena aqui analisada é central na narrativa desta ficção por diversas razões: primeiro, ela mostra como é possível adaptar o ambiente para receber uma pessoa com deficiência física. Esta é umas das primeiras cenas em que Luciana usufrui do espaço público, promovendo a inclusão, garantida pela Convenção (BRASIL, 2011) e defendida pelo Modelo Social. Este processo de promover a inclusão foi o que se presenciou na praia do Rio de Janeiro durante a visita a ONG. Pessoas com diversas deficiências, suas famílias e amigos e as outras pessoas que estavam ali, independentemente do projeto, interagindo e compartilhando o espaço. Neste caso, um ambiente completamente inóspito para quem tem deficiência física, torna-se acessível. Isto é o que prega o Modelo Social da Deficiência: o ambiente se adapta para receber as pessoas, de modo que quem experiencia uma deficiência possa participar das atividades do mesmo modo que qualquer outra pessoa. Segundo, o termo deficiência historicamente traz consigo a noção de insuficiência, entretanto, ao

R. Inter. Interdisc. INTERthesis, Florianópolis, v.13, n.3, p.61-80 Set.-Dez. 2016 
mostrar uma atividade sendo praticada ao ar livre e divulgar o papel do esporte, a telenovela está defendendo que deficiência e insuficiência não são sinônimos (HUGHES, 2002), reforçando, deste modo, a perspectiva do Modelo Social. Terceiro, a cena mostra o papel que o esporte tem na vida das pessoas com deficiência. Conforme se verificou nas diversas imersões em campo, o esporte é um dos grandes motivadores da vida destas pessoas e ele está intimamente ligado à inclusão social. Além disso, detalham-se alguns cuidados com o corpo da personagem, advindos de sua lesão, como é o caso da passagem de Luciana da cadeira de rodas para a cadeira anfíbia.

Contudo, diversos elementos da construção da cena levam a uma interpretação idealizada da vivência da deficiência. Um exemplo disto são os saltos do tempo do relato, em momentos em que a personagem necessita ajuda. Não sabemos como Luciana chegou ou foi embora da praia, não sabemos como trocou de roupa. A novela exclui situações em que a personagem necessita ajuda ou precisa ser tocada ou amparada por estranhos. Ocultam-se os momentos em que o corpo com lesão interage com o ambiente. Por outas palavras, se bem a lesão é mostrada, em certos momentos, a vivência da deficiência é escondida ou "não explicitada". Esta idealização também é dada pela reação da personagem. Na visita à ADAPTSURF, acompanhou-se o processo de chegada à praia de diversas pessoas com deficiência. Algumas delas já tinham usufruído do serviço oferecido pela ONG, e a entrada na água era tão rápida quanto a da telenovela. No entanto, havia pessoas que, assim como Luciana, estavam fazendo isso pela primeira vez. Este é o caso de Alexandre, um jovem de 18 anos que nasceu com paraplegia. Apesar de morar no Rio de Janeiro, esta era a primeira vez que entraria no mar. Ao conversar com ele, imediatamente respondeu: "não quero conversar, estou cansado. Quase não dormi a noite" (DIARIO DE CAMPO, Rio de Janeiro, 18/03/2012), denotando nervosismo.

Levou algumas horas até que Alexandre se sentiu seguro e decidiu entrar na água, sentado na cadeira anfíbia. O banho durou apenas uns minutos, e quando saiu e sentou em uma cadeira na areia sua irmã me disse: 'Faz algum tempo já que ele me pede para vir. Hoje finalmente conseguimos e ele está feliz, apesar de sentir medo' (DIARIO DE CAMPO, Rio de Janeiro, 18/03/2012).

O nervosismo prévio de Alexandre era completamente compreensível. Ele seria colocado numa cadeira de rodas dentro da água. Entraria no mar de costas, ou

R. Inter. Interdisc. INTERthesis, Florianópolis, v.13, n.3, p.61-80 Set.-Dez. 2016 
seja, não poderia ver as ondas que viriam em sua direção e, para completar, seria conduzido, o tempo todo, por pessoas que ele acabava de conhecer. É neste sentido que a telenovela idealiza a situação. Luciana estava na mesma condição de Alexandre, esta era a primeira vez que entrava no mar logo após o acidente, e nunca titubeou. Chegou à praia e entrou no mar sem a menor cerimônia, e o tempo todo riu e se divertiu.

No que diz respeito a narrativa transmidiática construída por Viver a vida e o blog Sonhos de Luciana, é interessante notar como ela estendeu a abordagem da deficiência em dois sentidos: no que tange aos textos, o blog tratou questões que não foram mostradas na telenovela ou foram abordadas de forma rápida, trazendo esclarecimentos, novas informações etc. Este é o caso, por exemplo, da explicação dos equipamentos que estavam na praia, fazendo parte do cenário, e não foram apresentados na cena, porém, aparecem detalhados na postagem do Dia 12 (Figura 7). No que tange a recepção, o blog ampliou a vivência coletiva, a comunidade estética (BAUMAN, 2003) gerada pela telenovela, criando outro espaço de recepção e interação. Gerou-se, igualmente, uma espécie de engajamento coletivo, onde telespectadores/as compartilharam suas percepções, vivências, conhecimentos e experiências sobre a deficiência. O blog permitiu criar um laço de "intimidade não recíproca" (THOMPSON, 2011) entre os/as telespectadores/as e Luciana, e este laço certamente contribuiu para a abordagem da deficiência, uma vez que as pessoas sentiram-se mais próximas à história. $\mathrm{O}$ blog quebrou a barreira geográfica. Pessoas de todo o Brasil, assim como de outros países seguiram e comentaram no blog. No caso das postagens sobre a visita à praia há, por exemplo, uma telespectadora do Canadá.

Através do blog ocorreu (e ainda ocorre, visto que continua disponível na internet) uma troca simbólica (THOMPSON, 2011) sobre o que é ser uma mulher com deficiência física adquirida, sobre suas rotinas, potencialidades, possibilidades, etc. Nesta troca pode perceber-se o 'jogo' que se estabelece entre o global e o local. Cada vez que um telespectador ou telespectadora de fora do Brasil faz seu comentário esclarece seu lugar de fala e, na grande maioria dos casos, compara o que é mostrado na telenovela com o contexto social do seu país, ocorrendo uma (re)apropriação do conteúdo. É possível reconhecer ainda outras formas de (re)apropriação, quando os telespectadores/as comentam sobre suas vivências,

R. Inter. Interdisc. INTERthesis, Florianópolis, v.13, n.3, p.61-80 Set.-Dez. 2016 
falam de sua história de vida, ou definem-se como pessoa com ou sem deficiência. Neste último caso, na grande maioria dos comentários, as pessoas sem deficiência reconheceram ter começado a pensar sobre a temática, ou até mesmo ter começado a observar o entorno e a refletir sobre as vivências das pessoas com deficiência. A telenovela Ihes abriu uma nova perspectiva. Já as pessoas com deficiência, normalmente procuraram relacionar sua história a de Luciana, falando sobre aspectos comuns ou divergências.

Ainda sobre a narrativa transmídia, vale citar a reportagem veiculada no jornalístico dominical da Rede Globo, Fantástico, que fez referência à visita de Luciana a praia. O diálogo entre os diferentes programas da emissora denotam a intenção da empresa em agendar a temática, colocá-la em pauta. Claro está que sua imagem institucional se beneficia com este tipo de abordagem; havendo também ganhos comerciais. Em termos de Garland-Thomson (2002), explora-se o diferente, o exótico, pois a deficiência vende. Por outro lado, este diálogo permite que o público tenha acesso a mais informações a respeito e as receba em diferentes formatos, diferenciando os produtos jornalísticos, que tem um compromisso com a realidade, e aqueles que são ficcionais, e buscam o entretenimento. É importante lembrar que, Viver a vida, assim como outras telenovelas que buscam estabelecer uma "ponte" com o contexto social, tem certo comprometimento com as temáticas que abordam, entretanto, seu principal compromisso é com a fantasia, com o entretenimento e não com a informação.

Finalmente vale um apontamento referente à perspectiva interdisciplinar. Sem dúvida ela foi a facilitadora desta análise. Sem a combinação de saberes da Comunicação, da Antropologia e dos Disability Studies não seria possível analisar a vivência da deficiência de modo amplo; observar o texto da telenovela, a linguagem audiovisual e o seu conteúdo conjuntamente; tecer conexões entre a telenovela, as postagens do blog e os comentários do público, estabelecer relações entre a telenovela e o contexto social de um modo integrador. Claro está que para cada pesquisa, para cada análise a combinação de saberes, a rede de conhecimentos, deverá ser diferente e este é outro dos grandes desafios da interdisciplinaridade: para cada pesquisa trilhar novo caminho.

R. Inter. Interdisc. INTERthesis, Florianópolis, v.13, n.3, p.61-80 Set.-Dez. 2016 


\title{
MEDIA AND DISABILITIES: AN INTERDISCIPLINAR APPROACH
}

\begin{abstract}
:
In this article we will reflect on the approach of the acquired physical disability proposed by the soap opera Viver a Vida (written by Manoel Carlos, produced and broadcast by Rede Globo in 2009 and 2010) and by the blog Sonhos de Luciana (REDE GLOBO, 2010). We will analyze the blog scene where Luciana, protagonist of this issue, goes for the first time to the beach after acquiring a disability. Starting from an interdisciplinary perspective, we establish a dialogue between three areas of knowledge. Social Communication (mainly Cultural Studies) supports the perspective from which we understand the media. Anthropology is the area that contributes to the look and methodology, the screen ethnography. And, finally, Disability Studies, that provide the theoretical basis for the analysis of disability.
\end{abstract}

Keywords: Soap Opera. Disability. Interdisciplinary. Screen Ethnography.

\section{MEDIOS DE COMUNICACIÓN Y DEFICIENCIA: UN ABORDAJE INTERDISCIPLINAR}

\section{Resumen:}

En este artículo reflexionaremos sobre el abordaje de la deficiencia física adquirida propuesta por la telenovela Viver a Vida (escrita por Manoel Carlos; producida y transmitida por Rede Globo en 2009 e 2010) y el blog Sonhos de Luciana (REDE GLOBO, 2010). Con esta finalidad, analizaremos la escena en que Luciana, protagonista de esta temática, visita la playa por primera vez después de haber adquirido la deficiencia. Partiendo de una perspectiva interdisciplinar se establece un diálogo entre tres áreas de conocimiento: la Comunicación Social (fundamentalmente los Estudios Culturales) que ampara la perspectiva a partir de la cual se comprenden los medios; la Antropología, área que contribuye con la mirada y la metodología, la etnografía de pantalla; y los Disability Studies, que aportan la base teórica para analizar la deficiencia.

Palabras clave: Telenovela. Deficiencia. Interdisciplinariedad. Etnografía de pantalla. 


\section{REFERÊNCIAS}

ASHENBURG, Katherine. Passando a limpo: o banho da Roma antiga até hoje. São Paulo: Larousse do Brasil, 2008.

BARBOSA, Andréa; DA CUNHA, Edgar Teodoro. Antropologia e imagem. Rio de Janeiro: Jorge Zahar, 2006.

BAUMAN. Zygmunt. Comunidade: a busca por segurança no mundo atual. Rio de Janeiro: Zahar, 2003.

BERENI, Laure; CHAUVIN, Sébastien; JAUNAIT, Alexandre; REVILLARD, Anne. Introduction aux études sur le genre. Bruxelles: De Boeck Supérierus s.a, 2012.

BRASIL. Secretaria de Direitos Humanos. Convenção sobre os Direitos das Pessoas com Deficiência (2007). 4. ed., rev. e atual. - Brasília: Secretaria de Direitos Humanos, Secretaria Nacional de Promoção dos Direitos da Pessoa com Deficiência, 2011. Disponível em: <http://www.pessoacomdeficiencia.gov.br/app/sites/default/files/publicacoes/convenc aopessoascomdeficiencia.pdf >. Acesso em: 4 mai. 2014.

CAILLAT, Colbie. Fallin'For you. In: Viver a vida Internacional. Brasil: Som Livre, 2009, 1 CD.Faixa 1.

DINIZ, Débora. O que é deficiência. São Paulo: Brasiliense, 2007.

DOUFOUR, PIERRE. L' homme en fauteuil: approche de genre Contribution à une sociologie critique du handicap. Université Toulouse 2 Le Mirail, Thèse Sociologie, 2011.

FANTÁSTICO. A cadeirante da vida real que inspira a Luciana de Viver a vida. 2010. Disponível em: <https://www.youtube.com/watch?v=ZNgB8PepC0c>. Acesso em: 14 mar. 2014.

FERNANDES, Valdir. Interdisciplinaridade: a possibilidade de reintegração social e recuperação da capacidade de reflexão na ciência. Revista Internacional Interdisciplinar INTERthesis. Florianópolis: PPGICH/ UFSC, v.7, n.2, jul/dez. 2010, p. 65-80. Disponivel em: <www.cfh.ufsc.br/interthesis>. Acesso em: 20 mar. 2011. 
GARLAND-THOMSON. Integrating Disability, transforming feminist theory. In: Feminist Formations, v. 14, n. 3, 2002, p. 1-32.

GENNEP, Arnold Van. Los ritos de paso. Madrid: Alianza Editorial, 2008.

GINSBURG, Faye. Não necessariamente o filme etnográfico: traçando um futuro para a antropologia visual. In: ECKERT, Cornélia; MONTE-MÓR, Patrícia (Orgs.). Imagem em foco: novas perspectivas em antropologia. Porto Alegre: Ed. Universidade/UFRGS, 1999, p.31-54.

GLOBO.COM. Dia 12 - Lá vem o sol, tchurururu!. Sonhos de Luciana. 2010b. Disponível em: <http://gshow.globo.com/novelas/viver-a-vida/sonhos-deluciana/platb/?s=dia+12>. Acesso: 12 out 2014.

GLOBO.COM . Dia 22 - Dia de luz, festa do sol. Sonhos de Luciana. 2010d. Disponível em: <http://gshow.globo.com/novelas/viver-a-vida/sonhos-deluciana/platb/?s=dia+22> Acesso: 15 out. 2014.

HUGHES, Bill. Disability and the body. In: BARNES, Colin; OLIVER, Mike; BARTON, Len (Orgs). Disability studies today. United States: Polity press, 2002, p.58-76.

JENKINS, Henry. Cultura da convergência. São Paulo: Aleph, 2009.

LOPES, Maria Immacolata Vassallo de; BORELLI, Silvia Helena Simões; RESENDE, Vera da Rocha. Vivendo com a telenovela: mediações, recepção, teleficcionalidade. São Paulo: Summus, 2002.

LOPES, Maria Immacolata Vassallo de (Org.) Ficção televisiva no Brasil: temas e perspectivas. São Paulo: Ed. Globo, 2009.

MELLO, Anahí Guedes de. Gênero, Deficiência, Cuidado e Capacitismo: uma análise antropológica de experiências, narrativas e observações sobre violências contra mulheres com deficiência. 2014. f. 154 Dissertação (Mestrado em Antropologia Social). Universidade Federal de Santa Catarina, Florianópolis, 2014.

OLIVER, Michael. Uniderstanding disability: from theory to practice. United Kingdom: Palagrave Macmillan, 2009. 
RIAL, Carmen. Antropologia e mídia: breve panorama das teorias de comunicação. Revista Antropologia em primeira mão. Florianópolis: Programa de Pós Graduação em Antropologia Social, 2004.

SHAKESPEARE, Tom. Disability, Normality, and Difference. In: COCKBURN, Jayne; PAWSON, Michael E. (Orgs). Psycological challenges in obstetrics and gynecology. London: Springer, 2007, p. 51-59.

THOMPSON, John B. A mídia e a modernidade: uma teoria social da mídia. Petrópolis: Vozes, 2011.

TURNER, Victor W. O processo ritual: estrutura e antiestrutura. Petrópolis: Vozes, 1974.

VIVER A VIDA. Autoria: Manoel Carlos. Direção: Adriana Melo, Teresa Lampreia, Maria Rodrigues, Leonardo Nogueira, Frederico Mayrink e Luciano Sabrino. Direção Geral: Jayme Monjardim e Fabricio Mamberti. Período de exibição: setembro 2009 a maio de 2010. Número de capítulos: 209.

WOLF, Mauro. Teorias das comunicações de massa. São Paulo: Martins Fontes, 2003.

\section{Artigo:}

Recebido em 12 de Novembro de 2015

Aceito em 13 de Julho de 2016

R. Inter. Interdisc. INTERthesis, Florianópolis, v.13, n.3, p.61-80 Set.-Dez. 2016 